\title{
Evaluation of the atmospheric significance of multiphase reactions in atmospheric secondary organic aerosol formation
}

\author{
A. Gelencsér ${ }^{1}$ and Z. Varga ${ }^{2}$ \\ ${ }^{1}$ Air Chemistry Group of the Hungarian Academy of Sciences, P.O. Box 158, H-8201 Veszprém, Hungary \\ ${ }^{2}$ Department of Earth and Environmental Sciences, University of Veszprém, Egyetem u. 10, H-8200 Veszprém, Hungary
}

Received: 4 May 2005 - Published in Atmos. Chem. Phys. Discuss.: 4 July 2005

Revised: 30 September 2005 - Accepted: 14 October 2005 - Published: 28 October 2005

\begin{abstract}
In a simple conceptual cloud-aerosol model the mass of secondary organic aerosol (SOA) that may be formed in multiphase reaction in an idealized scenario involving two cloud cycles separated with a cloud-free period is evaluated. The conditions are set to those typical of continental clouds, and each parameter used in the model calculations is selected as a mean of available observational data of individual species for which the multiphase SOA formation route has been established. In the idealized setting gas and aqueousphase reactions are both considered, but only the latter is expected to yield products of sufficiently low volatility to be retained by aerosol particles after the cloud dissipates. The key variable of the model is the Henry-constant which primarily determines how important multiphase reactions are relative to gas-phase photooxidation processes. The precursor considered in the model is assumed to already have some affinity to water, i.e. it is a compound having oxygen-containing functional group(s). As a principal model output an aerosol yield parameter is calculated for the multiphase SOA formation route as a function of the Henry-constant, and has been found to be significant already above $\mathrm{H} \sim 10^{3} \mathrm{M} \mathrm{atm}^{-1}$. Among the potential precursors that may be eligible for this mechanism based on their Henry constants, there are a suite of oxygenated compounds such as primary oxidation products of biogenic and anthropogenic hydrocarbons, including, for example, pinonaldehyde. Finally, the analogy of multiphase SOA formation to in-cloud sulfate production is exploited.
\end{abstract}

Correspondence to: A. Gelencsér

(gelencs@almos.vein.hu)

\section{Introduction}

Organic aerosol particles, in spite of their increasingly important role in key atmospheric processes such as radiative transfer or cloud formation, still constitute a puzzle to the atmospheric science community. Since their chemistry remains largely unresolved on the level of individual organic species, our understanding on their sources is still incomplete. To assess the role of human activities on these important atmospheric constituents with the help of more robust atmospheric models, much better insights into organic aerosol sources are needed. The concept of atmospheric organic tracers has been widely used for source apportionment of size-resolved aerosol in urban or metropolitan areas, especially in Los Angeles (Schauer et al., 1996). However, outside the immediate source regions, with increasing contribution from biogenic secondary aerosol sources for which the tracer approach does not work, source apportionment becomes uncertain and organic aerosol sources remain largely unknown. Therefore, over most of the troposphere, including rural and remote areas in the boundary layer and in the free troposphere where the contribution of organic aerosol to aerosol mass concentrations has been shown to be significant (Novakov et al., 1997) we know very little about the origin of this constituent. On the other hand, it is these regions and not the polluted boundary layer which determine a large part of the global effects of atmospheric aerosol, therefore better knowledge on sources of organic aerosol would be critically needed.

The first step towards a better understanding of sources which would also allow more thorough validation of global atmospheric models would be a more reliable assessment of the contributions of primary and secondary sources to organic aerosol mass concentrations. In atmospheric science, primary aerosol particles are those which are released

(C) 2005 Author(s). This work is licensed under a Creative Commons License. 
directly from mostly surface sources, such as soot particles from combustion or sea salt particles by bubble bursting from the oceans. In contrast, secondary particles form in the atmosphere by gas-to-particle transformations following (or preceding) photochemical reactions of directly emitted gaseous or volatile precursors. Among the major inorganic constituents of tropospheric fine aerosol, such as sulfate, nitrate or ammonium, secondary processes are of utmost importance. In contrast, on the global scale organic aerosol mass concentrations have been thought to be dominated by primary emissions, mostly from fossil fuel combustion and biomass burning (Penner et al., 2001). Although it is not straightforward to translate annual global emission inventories to relative share of primary versus secondary organic aerosol in the volume of the troposphere, a recent global model based on our current understanding of emissions and secondary organic aerosol (SOA) formation predicted that over the entire troposphere primary organic aerosol predominates (Chung and Seinfeld, 2002). On the other hand, regional scale SOA estimates predicted more significant relative contributions of SOA for rural and background regions (Castro et al., 1999; Brown et al., 2002). The most frequently used method to estimate the extent of SOA formation is based on the evolution of OC/EC ratio. In this concept SOA formation is manifested in the increase in OC/EC ratio of fine aerosol from source areas to rural and background regions (Turpin and Huntzicker, 1991). The method assumes no bias for the determination of elemental carbon (EC) which is considered as a conservative tracer for primary combustiongenerated OC emissions. Although these statements are at least questionable, uncertainties are generally understood to arise in the estimation of a characteristic primary OC/EC ratio (Strader et al., 1999; Lim and Turpin, 2002). Using this approach, even urban areas showed relative high SOA contributions in summer (mean $46 \%$ in Atlanta, but at times as much as $88 \%$ of the 1 -h average OC concentrations) (Lim and Turpin, 2002). On an annual basis, at a receptor site in the South Californian Air Basin under strong anthropogenic influence, between $27 \%$ and $38 \%$ of the organic carbon was assigned to be of secondary origin (Gray, 1986). Furthermore, recent studies in more pristine regions such as national parks indicate an even higher share of SOA (between 42 and 98\% for the period of July-October in Texas) (Brown et al., 2002). In Portugal, SOA contribution to fine OC was estimated to be $45 \%$ and $68-78 \%$ for winter and summer, respectively (Castro et al., 1999).

The general understanding of atmospheric SOA formation is that it mainly occurs by the photochemical reactions of volatile organic compounds (VOCs) and the subsequent condensation of low volatility reaction products onto preexisting aerosol particles. Among the VOCs involved in SOA formation biogenic unsaturated compounds predominate (Griffin et al., 1999), the primary mechanism of gasto-particle transformation is absorptive partitioning into the organic phase (Odum et al., 1996).
Very recently there has been mounting evidence that other processes such as heterogeneous and multiphase reactions in the troposphere could induce significant SOA formation in addition to the abovementioned mechanism. The distinction between heterogeneous and multiphase reactions which are constrained to the surface of solid particles and take place in the bulk of hydrometeors, respectively, follows the recommendations by Ravishankara (1997). Heterogeneous reactions are expected to result in a drastic reduction in the equilibrium vapor pressure of the SOA products thereby increasing aerosol yield (Jang et al., 2002). Acid-catalyzed carbonyl chemistry on aerosol particles, which are essentially interactions between the organic and inorganic components of tropospheric aerosol, includes hydration, hemiacetal and acetal formation, aldol condensation, and polymerization in the aerosol phase. Recent smog-chamber experiments in combination with laser desorption/ionisation mass spectrometry measurements have shown that semi-volatile photooxidation products of 1,3,5-trimethylbenzene tend to polymerize in the aerosol phase in reactions catalyzed only by the semi-volatile acidic reaction products (Kalberer et al., 2004). Another recent smog-chamber study on the effect of acidic seeds on $\alpha$-pinene ozonolysis has inferred that acidity promotes SOA formation and increases aerosol yield by up to $40 \%$ (Iinuma et al., 2004). The first laboratory evidence for the irreversible formation of polymeric species in heterogeneous reactions on sulfuric acid has been presented recently for isoprene (Limbeck et al., 2003). The conclusions drawn from these bulk experiments were that isoprene, whose SOA formation has been thought previously to be negligible (Pandis et al., 1991), may contribute to SOA formation through this mechanism. On the molecular level, the possibility of isoprene photooxidation in acid catalyzed reactions has been supported by the identification of two diastereoisomers of a polyol with a $\mathrm{C}_{5}$ isoprene skeleton, 2-methylthreitol and 2methylerythritol in forest aerosol (Claeys et al., 2004a).

Although it is well established that in the troposphere a major part of sulfate is formed in reactions in cloud droplets multiphase organic chemistry is still in its infancy. This might be surprising because the possibility of VOC oxidation in cloud and fog droplets was first raised more than 20 years ago (Graedel and Goldberg, 1983). Aqueous-phase OH reactions in cloud and fog droplets were proposed as pathways for the oxidation of aldehydes to their corresponding carboxylic acids (Chameides, 1984; Graedel et al., 1986; Cho and Carmichael, 1986; Seinfeld and Pandis, 1989). The first laboratory evidence for multiphase polymerization reactions of lignin pyrolysis products in the troposphere has been presented very recently (Gelencsér et al., 2003; Hoffer et al., 2004). The in-cloud formation of oxalic acid from acetylene and ethene in the marine atmosphere has been quantitatively evaluated in a simple model by Warneck (2003). The calculated production rate has been found to largely account for available observations of oxalic acid mass concentrations in the Central Pacific (Kawamura and Sakaguchi, 1999). The 
suggested oxidation scheme has received additional support from the detection of intermediates glyoxal and glyoxylic acid in marine precipitation (Sempere and Kawamura, 1996). The proposed mechanism which includes gas-phase photooxidations, gas-to-particle transfer of intermediates driven by further photooxidation reactions in the aqueous phase, clearly represents a new route for SOA formation previously not considered in atmospheric models. This is because partitioning of semi-volatile intermediates into the aerosol phase would be insignificant (therefore negligible SOA mass formation would be inferred by the traditional SOA mechanism) without the aqueous-phase reactions which consume the hydrated species thereby maintaining a flux from the gas phase to the droplet phase. Furthermore, upon the dissipation of the cloud the end-product oxalic acid is not expected to return to the gas phase because of its very low volatility (Clegg et al., 1996). However, recent studies have indicated that significant fraction of oxalic acid can be found in the gas phase contrary to what simple partitioning theory would predict (Baboukas et al., 2000; Limbeck et al., 2005). The in-cloud mass production of $\mathrm{C}_{2}-\mathrm{C}_{6}$ dicarboxylic acids and pyruvic acid has also been calculated in a cloud parcel model for clean and polluted continental conditions (Ervens et al., 2004a). The volatile precursors considered were toluene, ethylene, cyclohexene, and isoprene, and the model was run for several cloud cycles. The organic mass additions for the clean and polluted scenario were found to be $\sim 150 \mathrm{ng} \mathrm{m}^{-3}$ and $\sim 400 \mathrm{ng} \mathrm{m}^{-3}$, respectively. It should be noted, however, that in this case the total liquid water content was not allowed to fall below $1 \mathrm{mg} \mathrm{kg}^{-1}$ after any cloud cycle (i.e. the droplets were not allowed to return to ambient aerosol state). This inevitably means that a substantial fraction of semi-volatile organic species were retained between cloud cycles which would have otherwise evaporated, therefore the model may not be the best quantitative approach for the abovementioned new SOA formation mechanism.

In this paper we adopt a simple conceptual model for cloud processing to evaluate the potential significance of the new SOA formation mechanism in the global atmosphere and to constrain the range of precursors that might be eligible for this mechanism. This effort pursues the tempting analogy of sulfate production in clouds in the realm of organic chemistry, i.e. whether multiphase processes could induce significant SOA mass production in excess of the conventional mechanism, perhaps even from organic precursors previously not considered to be significant in SOA formation.

\section{Conceptual model for multiphase SOA formation}

The conceptual model uses a fixed and idealized atmospheric scenario to help follow the course of multiphase SOA formation and evaluate its atmospheric significance. Being a conceptual model, it does not rely on the specific physicalchemical properties of any given organic photooxidation sys- tem, including reaction rates, equilibrium constants, and equilibrium vapor pressure of precursors and products. However, the selection of these key parameters is constrained by observed properties of several reaction systems of atmospheric relevance. This simple approach helps keep track of the process itself without being lost in the extreme complexity of atmospheric multiphase systems. Advanced multiphase chemistry models that have recently become available have just started to evaluate the in-cloud production of low molecular weight dicarboxylic acids as abundant low volatility aerosol constituents (Warneck, 2003; Ervens et al., 2004a). In spite of the existence of such models, our approach may help assess the significance of this new formation pathway relative to the conventional SOA formation mechanism that has long been included in atmospheric models of regional and global scale. Furthermore, it may allow us to explore the analogy with the well-established in-cloud sulfate production in order to shed light on the potential global importance of the process. And last but not least our model may promote further studies on this field by constraining the range of compounds that might be eligible for this new SOA formation route.

The scheme of our conceptual model is depicted in Fig. 1. The model starts from a semi-volatile organic precursor (SVOC) that already has some affinity for water. Such compounds may either be directly emitted by natural and anthropogenic sources or formed as first generation products by the photooxidation of VOCs. The list of potential precursors can be found in the excellent review by Saxena and Hildemann (1996). Although of the two source types the latter is clearly predominant in most environments, it is outside the scope of this paper to include gas-phase formation of the precursor. The model starts with an air parcel containing the precursor at a fixed overall mixing ratio of $10 \mathrm{ppt}$ in which a cloud with a total liquid water content (LWC) of $0.3 \mathrm{~g} \mathrm{~m}^{-3}$ consisting of $10 \mu \mathrm{m}$ droplets is allowed to form instantaneously at a temperature of $288 \mathrm{~K}$. The cloud is assumed to persist for $1 \mathrm{~h}$ then dissipates and the compounds formed are either vented to the gas-phase or remain in the aerosol phase depending on their equilibrium vapor pressure through absorptive partitioning. This cloudless period lasts for $8 \mathrm{~h}$ then a cloud with the same parameters forms again for one additional hour. In the model, aerosol formation is evaluated for the overall process consisting of three elementary stages.

As regards mass balance, the system is considered to be closed, i.e. the precursor is not replenished by photochemical reactions in the gas-phase. While this constraint may not be suitable for precursors formed from long-lived gaseous species such as acetylene or from those whose emission sources are widely distributed, it may be reasonable for photooxidation products of highly reactive volatile organic compounds. In any case, this approach places a lower limit for the yield of cloud chemical processes. The upper limit would be to assume an open system, i.e. steady-state gasphase mixing ratio of the precursor throughout the duration 


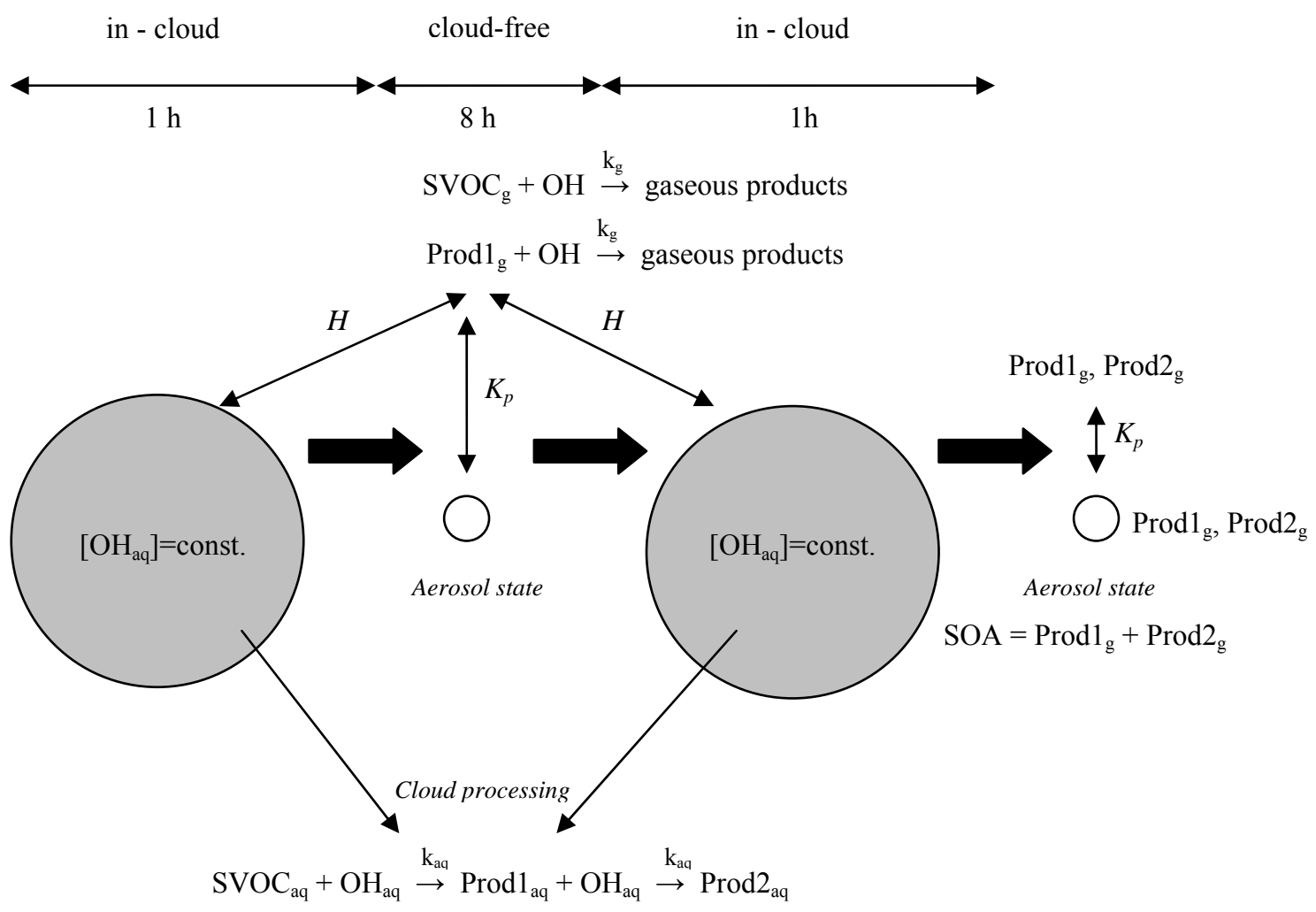

Global liquid phase reaction rate

$$
-\frac{d[G]}{d t}=A R T H \sqrt{D_{l} \Sigma k_{a q}}[G]
$$

Fig. 1. Scheme of the conceptual model $(1 \mathrm{~h}$ in cloud $-8 \mathrm{~h}$ cloudless $-1 \mathrm{~h}$ in cloud). Initial mixing ratio of SVOC is $10 \mathrm{ppt} \mathrm{C}$. Global liquid phase reaction rate term is from Ravinshankara (1997). Kp is the absorption partitioning constant defined by Pankow (1994). $H$ is the Henrys law constant.

of the entire cloud cycle. In the cloud the equilibrium of the precursor between the gas and droplet phase is established according to Henry's law. This assumption is a simplification since it has been shown that achievement of thermodynamic equilibrium may take several minutes (if established at all) in clouds due to transport processes (Winiwarter et al., 1994; Audiffren et al., 1998). Therefore the yields of aqueous-phase processes are likely overestimated. Nevertheless, Henry's constant turns out to be the key variable in the process which primarily determines the importance of multiphase SOA formation with respect to gas-phase photooxidation. At $\mathrm{t}=0$ photooxidation is allowed to start both in the gas and droplet phase assuming steady-state oxidant concentrations in both phases. For $\mathrm{OH}$ radical concentrations steady-state values of $2.5 \times 10^{6} \mathrm{~cm}^{-3}$ and $5 \times 10^{-13} \mathrm{M}$ are set for the gas and aqueous phase, respectively (Warneck, 2003; Lelieveld and Crutzen, 1991).

Second-order gas-phase reaction rate for all species is assumed to be $1 \times 10^{-11} \mathrm{~cm}^{3}$ molecule ${ }^{-1} \mathrm{~s}^{-1}$, derived as a mean from experimental rate constants of various oxygenated compounds (Calogirou et al., 1999; Glasius et al., 2000; Hallquist et al., 1997; Atkinson, 1989). Similarly, for aqueous-phase reaction rates a single value of $5 \times 10^{8} \mathrm{M}^{-1} \mathrm{~s}^{-1}$ is assumed for all species (Dutot et al., 2003). Mass transfer from the gas phase is accounted for using "global reaction rate expression" by Ravishankara (1997). It is defined as the overall first-order rate coefficient for the loss of reactant in the liquid phase, which combines the resistances of elementary steps such as gas-phase diffusion, mass accommodation, diffusion in the droplet, and the rates of chemical reactions. While the product of the gasphase photooxidation reaction is not considered any further it is assumed that the equilibrium vapor pressure and Henry constant of the first generation product of the aqueous-phase reaction has decreased by a factor of 100 and increased by a factor of 1000 , respectively, relative to those of the precursor. These assumptions are based on the properties of intermediates in relevant in-cloud reactions leading to the formation 
of dicarboxylic acids as reported by Ervens et al. (2004a) and Warneck (2003). This first generation reaction product (Prod1)as intermediate in the process is assumed to react further in the aqueous phase yielding a second generation product of low volatility. Gas-phase reaction of this intermediate is also considered as a sink but its product is deemed too volatile to contribute to aerosol mass. For simplicity, the rates of the reactions are assumed to be the same as those of the precursor. The second generation product of the aqueousphase reaction (Prod2)is assumed to have an equilibrium vapor pressure by a factor of $10^{6}$ lower than that of the initial precursor based on relevant references (Ervens et al., 2004a; Warneck, 2003). The sensitivity of the system to the equilibrium vapor pressure of the intermediate and the end-product is evaluated by varying the prescribed vapor pressure reduction by a factor of 10 and 100, respectively, upwards and downwards.

The duration of the cloud event is set to $1 \mathrm{~h}$, after which the cloud dissipates and equilibrium between the gas and aerosol phase is established for both the precursor and products. This process releases the precursor and a large fraction of its firstgeneration product back to the gas-phase. The equilibrium between the gas and aerosol phase is evaluated by the absorptive partitioning theory by Pankow (1994). Here the key parameter is the equilibrium vapor pressure which is assumed to be $5 \mathrm{~Pa}$ at $288 \mathrm{~K}$ for the precursor. The activity coefficient $\left(\xi_{i}\right)$, the mass concentration of total suspended particulate matter, the average molecular weight and aerosol mass fraction of the absorbing organic phase are assumed to be unity, $1 \mu \mathrm{g} \mathrm{m}^{-3}, 300 \mathrm{~g} \mathrm{~mol}^{-3}$, and 0.3 , respectively. It should be noted that there have been more and more indications in the literature that this simple partitioning theory fails to adequately describe gas-to-aerosol partitioning of many semi-volatile compounds in the atmosphere. Although this clearly adds to the uncertainties of our model, it is beyond the scope of the paper to address this issue any further.

Then follows a cloud-free period of $8 \mathrm{~h}$ during which only gas-phase reactions proceed. Then another cloud cycle occurs which lasts for another $1 \mathrm{~h}$, in-cloud equilibrium is reestablished and aqueous-phase reactions resume. The cloud parameters are the same as in the initial case. The process ends with the dissipation of the cloud and the reestablishment of equilibrium between the gas and aerosol based on the principles above. The model is a simple numerical model calculating incremental mass changes in both the gas and aqueous phase then reestablishing equilibrium between the phases after each elementary time-step.

As the principal model output the overall SOA formation per unit volume of air is calculated as the sum of the carbon mass concentrations of primary and secondary products that remain in the aerosol phase at the end. The concentrations of all species are expressed on a carbon mass basis. Furthermore, it is important to stress that ambient aerosol state is considered here, unlike the advanced model by Ervens et al. (2004a) which does not allow liquid water content to fall

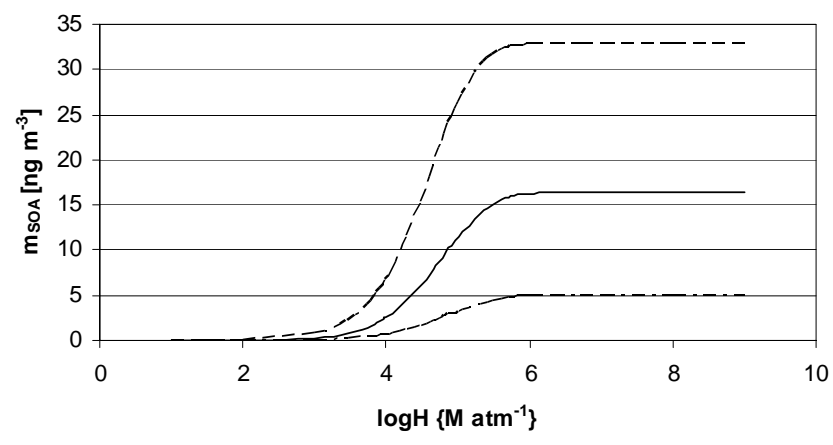

Fig. 2. Aerosol mass production of multiphase reactions per unit volume of air as a function of the logarithm of the Henry constant of the precursor for the idealized scenario considered $(1 \mathrm{~h}$ in cloud $-8 \mathrm{~h}$ cloudless $-1 \mathrm{~h}$ in cloud). Initial mixing ratio of the precursor is $10 \mathrm{ppt} C$. Middle curve: with $k_{\mathrm{gas}}=2.5 \times 10^{-5} \mathrm{~cm}^{3}$ molecule $\mathrm{s}^{-1} \mathrm{~s}^{-1}, k_{\text {aqueous }}=2.5 \times 10^{-4} \mathrm{M}^{-1} \mathrm{~s}^{-1}$; upper curve: with $k_{\text {gas }}=1.25 \times 10^{-5} \mathrm{~cm}^{3}$ molecule $\mathrm{s}^{-1}, \quad k_{\text {aqueous }}=5 \times 10^{-4} \mathrm{M}^{-1}$ $\mathrm{s}^{-1}$; lower curve: with $k_{\mathrm{gas}}=5 \times 10^{-5} \mathrm{~cm}^{3}$ molecule $\mathrm{s}^{-1} \mathrm{~s}^{-1}$, $k_{\text {aqueous }}=1.25 \times 10^{-4} \mathrm{M}^{-1} \mathrm{~s}^{-1}$.

below $1 \mathrm{mg} \mathrm{m}^{-3}$ after any cloud cycle. Another key output of the model is the aerosol yield $(Y)$ of the entire process, which is defined as the ratio of the mass of aerosol formed to the mass of the precursor reacted, exactly the same as for interpreting smog-chamber experiments (Hoffmann et al., 1997). In addition, the model allows the calculation of the relative contributions of gas- and aqueous phase reactions over the entire process. The model outputs are expressed as a function of Henry's constant which is the only variable in this conceptual model. This model helps evaluate the role of Henry's constant in multiphase SOA formation, assess the magnitude of the process and compare it to in-cloud sulfate formation. Furthermore, with the range of Henry' constants constrained, potential precursors can be selected from the compilation by Saxena and Hildemann (1996) which, when combined with the retrospective approach to gas-phase formation mechanisms by Pun et al. (2000), may allow the identification of primary VOCs that might contribute to SOA formation via this mechanism.

\section{Results and discussion}

The total mass of aerosol carbon formed in unit volume of air in the two 1-h cloud events separated with an 8-h cloudless period is shown in Fig. 2 as a function of the Henryconstant of the precursor, with the set parameters detailed in the model description. In the same figure, two limiting cases are also depicted: the low bound (in terms of aerosol mass production) when the rate of the gas-phase reaction is increased and that of the aqueous-phase reaction is decreased by a factor of 2 each; and the high bound vice versa. These constrain a range for the given scenario which could 


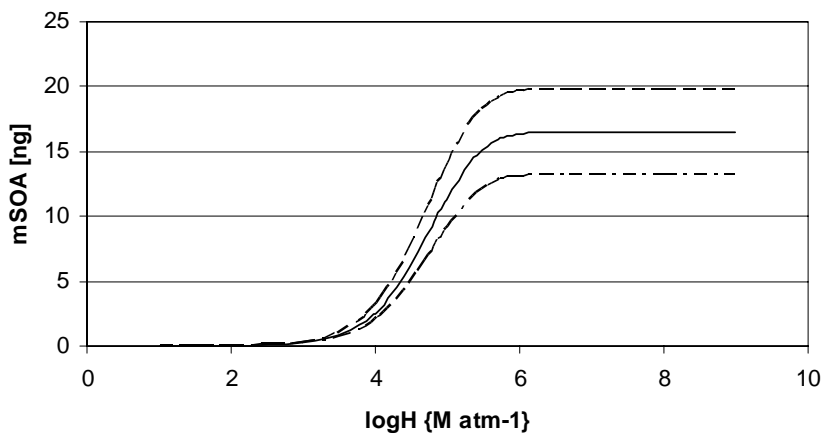

Fig. 3. Aerosol mass production of multiphase reactions per unit volume of air as a function of the logarithm of the Henry constant of the precursor for the idealized scenario considered $(1 \mathrm{~h}$ in cloud $-8 \mathrm{~h}$ cloudless $-1 \mathrm{~h}$ in cloud). Initial mixing ratio of the precursor is 10 pptC. $k_{\text {gas }}=2.5 \times 10^{-5} \mathrm{~cm}^{3}$ molecule ${ }^{-1} \mathrm{~s}^{-1}$, $k_{\text {aqueous }}=2.5 \times 10^{-4} \mathrm{M}^{-1} \mathrm{~s}^{-1}$; Middle curve: ratios of equilibrium vapour pressure of Prod 1 and Prod 2 to that of SVOC are $10^{-2}$ and $10^{-6}$, respectively; the same as the middle curcve in Fig. 2; upper curve: ratios of equilibrium vapour pressure of Prod 1 and Prod 2 to that of SVOC are $10^{-3}$ and $10^{-8}$, respectively. lower curve: ratios of equilibrium vapour pressure of Prod1 and Prod2 to that of SVOC are $10^{-1}$ and $10^{-4}$, respectively.

give reasonable estimates provided that the other assumptions (e.g. reduction of Henry-constants and equilibrium vapor pressures from precursors to first- and second-generation products) are valid.

All curves in Fig. 2 show a steep increase starting above $\mathrm{H} \sim 10^{3} \mathrm{Matm}^{-1}$, and a plateau from less than $\mathrm{H} \sim 10^{6} \mathrm{M} \mathrm{atm}^{-1}$ which indicates that during the cloud events virtually all species reside and are oxidized in the droplets. It is also obvious that the production rate is very sensitive to Henry constant in a relatively confined range between $\mathrm{H} \sim 10^{3}$ and $5 \times 10^{4} \mathrm{Matm}^{-1}$, but its magnitude is also strongly dependent on the rates of the gas-phase and aqueous-phase reactions. In other terms, it is primarily the Henry-constant which determines whether multiphase aerosol production is possible or not. If yes, the reaction rates will determine its magnitude and significance relative to gas-phase photooxidation processes. The sensitivity of the system to the prescribed vapor pressure reduction is shown in Fig. 3. As it can be seen in Fig. 3, the aerosol carbon mass formed is not excessively sensitive to a 10- and 100fold change in the vapor pressure of the intermediate and end-product, respectively, either upwards or downwards relative to the base case also shown in Fig. 2. However, combination of the sensitivities shown in Fig. 2 and Fig. 3. would yield more than an order of magnitude difference between the low and high estimates.

From the model it is also possible to calculate aerosol yield $(Y)$ as a function of the logarithm of the Henry-constant. It is shown in Fig. 4, together with the low and high bound estimates specified above. The aerosol yield of the precursor

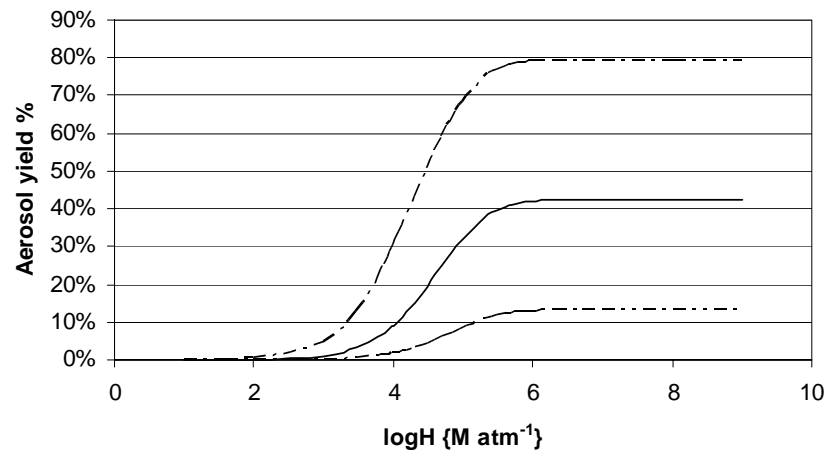

Fig. 4. Aerosol yield of multiphase reactions as a function of the logarithm of the Henry constant of the precursor for the idealized scenario considered $(1 \mathrm{~h}$ in cloud $-8 \mathrm{~h}$ cloudless $-1 \mathrm{~h}$ in cloud). Middle curve: with $k_{\text {gas }}=2.5 \times 10^{-5} \mathrm{~cm}^{3}$ molecule $\mathrm{e}^{-1} \mathrm{~s}^{-1}, k_{\text {aqueous }}=2.5 \times 10^{-4} \mathrm{M}^{-1} \mathrm{~s}^{-1}$; upper curve: with $k_{\text {gas }}=1.25 \times 10^{-5} \mathrm{~cm}^{3}$ molecule $\mathrm{s}^{-1}, k_{\text {aqueous }}=5 \times 10^{-4} \mathrm{M}^{-1}$ $\mathrm{s}^{-1}$; lower curve: with $k_{\text {gas }}=5 \times 10^{-5} \mathrm{~cm}^{3}$ molecule $\mathrm{s}^{-1}$, $k_{\text {aqueous }}=1.25 \times 10^{-4} \mathrm{M}^{-1} \mathrm{~s}^{-1}$.

shows a wide span from being negligible to very significant in almost the same $\log H$ range as absolute aerosol mass concentrations in Fig. 2. Remember that the aerosol yield specifies how much aerosol is formed (on a carbon mass basis) relative to the fraction of precursors reacted - it is therefore a direct measure of the importance of aerosol formation versus gas-phase loss processes. Additionally, it should be noted that the value of $Y$ refers to the actual atmospheric scenario modeled; it may be substantially different if other scenarios were set. With this in mind, aerosol yields can be used to link cloud-processing to the much better known gas-phase photooxidation mechanisms, since the precursors considered here are first- or second order reaction products of gas phase processes. Knowing the stoichiometry of gas-phase photooxidation of a parent VOC to its oxygenated product - which is actually the precursor of cloud-processing -, and the aerosol yield of the precursor, one should be able to assess the importance of multiphase SOA formation from the given parent compound, at least for the scenario considered.

The minimum value of Henry constant that is needed to furnish non-negligible secondary organic aerosol formation by cloud processes in the given scenario is about $\mathrm{H} \sim 10^{3} \mathrm{M} \mathrm{atm}^{-1}$. This constrains the range of potential precursors that might be eligible for this mechanism. One should remember that the parameters of this conceptual model are non-specific, therefore for any individual species it can only be regarded as very rough indication for the likelihood that such multiphase processes might or might not be important. Verification of potential pathways should involve experimental evidence that consecutive aqueous-phase oxidation reactions do occur under conditions relevant in tropospheric cloud water, identification and determination of the physico-chemical properties of the products formed and the determination of the rates of the reactions. Preferably, 
potential pathways should be evaluated in more advanced multiphase chemistry models such CAPRAM (Hermann et al., 2000), or those developed by Ervens et al. (2004a, b) and Warneck (2003).

Among potential candidates, glyoxal and glycolaldehyde, formed by the gas-phase photooxidation of acetylene and ethene, respectively, both turn out be important precursors for multiphase secondary aerosol formation having effective Henry-constants $3.4 \times 10^{5}$ and $4.14 \times 10^{4} \mathrm{M} \mathrm{atm}^{-1}$, respectively (Betterton and Hoffmann, 1988). Alternatively, glyoxal may also be formed by the photooxidation of toluene (Ervens et al., 2004a). In fact, the significance of these incloud chemical processes has already been firmly established in a recent model study on the formation of oxalic acid in the marine atmosphere (Warneck, 2003). In general, multifunctional organic compounds may appear to be potential precursors for multiphase aerosol production. For example, hydroxyacetone which is produced by isoprene photooxidation (Yu et al., 1995) may fall in this category based on its Henry constant $\left(2 \times 10^{4} \mathrm{M} \mathrm{atm}^{-1}\right)$ (Klotz et al., 1999). The aqueous-phase oxidation of hydroxyacetone has been investigated by Stefan and Bolton (1999). Similarly, pinonaldehyde, the primary product of the gas-phase reactions of $\alpha$ pinene with ozone and $\mathrm{OH}$ also seems to be eligible for this mechanism based on its estimated Henry constant of $\mathrm{H} \sim 9 \times 10^{3} \mathrm{M} \mathrm{atm}^{-1}$ (Meylan and Howard, 1991). Other potential bifunctional precursors include 3-hydroxypropanoic acid $\left(\mathrm{H} \sim 3.7 \times 10^{7} \mathrm{Matm}^{-1}\right)$ which may be formed from (Z)-3-hexen-1-ol (leaf alcohol) emitted by vegetation (Pun et al., 2000). The photooxidation of unsaturated oxygencontaining compounds (e.g. 2-methyl-3-buten-2-ol) emitted in substantial amounts by plant species in Europe (König et al., 1995) is expected to yield hydroxy carbonyls (Grosjean et al., 1993) which might also be aerosol precursors through the multiphase route.

On the contrary, methacrolein, a primary photooxidation product of isoprene, whose aqueous phase transformation to 2,3-dihydroxymethacrylic acid by hydrogen peroxide has been successfully demonstrated in the laboratory (Claeys et al., 2004b), has far too low effective Henry constant $\left(6.5 \mathrm{M} \mathrm{atm}^{-1}\right)$ (Iraci et al., 1998) to support multiphase aerosol formation against gas-phase photooxidation processes. However, a gas-phase photooxidation product of methacrolein, methacrylic acid, which has also been shown to yield 2,3-dihydroxymethacrylic acid upon reaction with hydrogen peroxide in the aqueous phase (Claeys et al., 2004b), may turn out to be a potential precursor for multiphase SOA formation based on its moderate Henry constant of $2 \times 10^{3} \mathrm{M} \mathrm{atm}^{-1}$ (Meylan and Howard, 1991). It should be added that under certain conditions low solubility species may also contribute to mass formation, for example, if their uptake is greatly enhanced by interaction with other dissolved species.

Finally, one important issue remains, namely how multiphase SOA formation relates to sulfate formation in in-cloud processes. Gas-phase $\mathrm{SO}_{2}$, on account of its acid-base properties and chemical interactions with other soluble species such as formaldehyde (Klippel and Warneck, 1978), is a highly soluble gas which has an effective Henry constant well within the range that has been shown to be important in multiphase oxidation processes. Secondly, gas-phase oxidation rate of $\mathrm{SO}_{2}$ by $\mathrm{OH}$ is lower than those of most organic compounds, while typical aqueous phase oxidation rates of $\mathrm{SO}_{2}$ - though the mechanism of oxidation is rather complex and $\mathrm{pH}$-dependent - are about an order of magnitude higher than that of most organic species at $\mathrm{pH}$ typical of cloud water (Warneck, 1988; Dutot et al., 2003). But most importantly, $\mathrm{SO}_{2}$ oxidation produces the essentially non-volatile sulphuric acid in a single step while SOA formation requires at least two consecutive reactions to yield low-volatility multifunctional products that remain in the aerosol phase after the dissipation of the cloud. Additionally, photooxidation of organic compounds may also yield gaseous by-products which also leads to reduced SOA formation efficiency compared to that of $\mathrm{SO}_{2}$ oxidation. All these factors make multiphase SOA formation less effective per unit mass concentration of the precursor than in-cloud sulfate production. Nevertheless, considering the vast amounts of VOCs that are emitted by vegetation and oxidized in the troposphere this process may still represent an important route for organic aerosol mass production. Last but not least this mechanism may bring into focus new volatile species that are not primarily important in terms of mass emission relative to natural hydrocarbons but have high aerosol yields through the multiphase route.

\section{Conclusions}

This study establishes multiphase photooxidation as a potentially significant source of secondary organic aerosol (SOA) with the help of a simple conceptual cloud-aerosol chemistry model using a fixed and idealized atmospheric scenario. The model is based on the assumption that aqueous reactions of organic species with $\mathrm{OH}$ radicals yield an essentially non-volatile product in two consecutive reaction steps. In the model overall aerosol production is evaluated as a function of the Henry constant of the precursor. The results show that there is a limit in aqueous solubility of organic photooxidation products or of directly emitted oxygenated compounds above which their contribution to SOA formation via in-cloud oxidation processes needs to be critically evaluated. This limit corresponds to Henry constant of about $10^{3} \mathrm{M} \mathrm{atm}^{-1}$ which qualifies many bifunctional compounds and carbonyls of larger molecular weight such as pinonaldehyde as potential precursors for the process. For compounds that has qualified the aerosol yield of an idealized scenario involving two cloud cycles separated with a cloudless period varies from about $1 \%$ to over $70 \%$, strongly depending on the relative rates of gas-phase and aqueous 
phase photooxidation reactions. While ample data have been available for the former, unfortunately very little is known about the mechanisms and rates of aqueous-phase organic oxidation reactions. Although multiphase SOA formation is clearly a less efficient process than in-cloud sulfate production per unit mass concentration of the precursor, it may significantly contribute to atmospheric SOA production on a global scale. However, much better understanding of cloud organic chemistry is needed before the significance of this process can be assessed with a tolerable level of certainty.

Acknowledgements. The authors are grateful to the Hungarian Scientific Foundation (OTKA Project No. T043578, TS049845), and the NKFP grant No. 3A/089/04 for their financial support.

Edited by: A. B. Guenther

\section{References}

Atkinson, R.: Kinetics and mechanisms of the gas phase reactions of the hydroxyl radical with organic compounds, J. Phys. Chem. Ref. Data, Monograph 1, 1-246, 1989.

Audiffren, N., Renard, N., Buisson, E., and Chaumerliac, N.: Deviations from the Henrys Law equilibrium during cloud events: a numerical approach of the mass transfer between phases and its specific numerical effects, Atmos. Res., 49, 139-161, 1998.

Baboukas, E. D., Kanakidou, M., and Mihalopoulos, N.: Carboxylic acids in gas and particulate phase above the Atlantic Ocean, J. Geophys. Res., 105, 14 459-14 471, 2000.

Betterton, E. A. and Hoffmann, M. R.: Henry's law constants of some environmentally important aldehydes, Environ. Sci. Technol., 22, 1415-1218, 1998.

Brown, S. G., Herckes, P., Ashbaugh, L., Hannigan, M. P., Kreidenweis, S. M., and Collett, J. L.: Characterization of organic aerosol in Big Bend National Park, Texas, Atmos. Environ., 36, 5807-5818, 2002.

Calogirou, A., Larsen, B. R., and Kotzias, D.: Gas-phase terpene oxidation products: a review, Atmos. Environ., 33, 1423-1439, 1999.

Castro, L. M., Pio, C. A., Harrison, R. M., and Smith, D. J. T.: Carbonaceous aerosol in urban and rural European atmospheres: estimation of secondary organic carbon concentrations, Atmos. Environ., 33, 2771-2781, 1999.

Chameides, W. L.: The photochemistry of a remote marine stratiform cloud, J. Geophys. Res., 89, 4739-4755, 1984.

Cho, S. Y. and Carmichael, G. R.: Sensitivity analysis of the role of free-radical, organic and transition-metal reactions in sulfate production in clouds, Atmos. Environ., 20, 1959-1968, 1986.

Chung, S. H. and Seinfeld, J. H.: Global distribution and climate forcing of carbonaceous aerosols, J. Geophys. Res., 107, 4407, doi:10.1029/2001JD001397, 2002.

Claeys, M., Graham, B., Vas, G., Wang, W., Vermeylen, R., Pashynska, V., Cafmeyer, J., Guyon, P., Andreae, M. O., Artaxo, P., and Maenhaut, W.: Formation of secondary organic aerosols through photooxidation of isoprene, Science, 303, 1173-1176, 2004a.

Claeys, M., Wang, W., Ion, A. C., Kourtchev, I., Gelencsér, A., and Maenhaut, W.: Formation of secondary organic aerosols from isoprene and its gas-phase oxidation products through reac- tion with hydrogen peroxide, Atmos. Environ., 38, 4093-4098, 2004b.

Clegg, S. L., Brimblecombe, P., and Khan, I.: The Henry's law constant of oxalic acid and its partitioning into the atmospheric aerosol, Idöjárás, 100, 51-68, 1996.

Dutot, A. L., Rude, J., and Aumont, B.: Neural network method to estimate the aqueous phase rate constant for the $\mathrm{OH}$ reactions with organic compounds, Atmos. Environ., 37, 269-276, 2003.

Ervens, B., Feingold, G., Frost, G. J., and Kreidenweis, S. M.: A modeling study of aqueous production of dicarboxylic acids: 1. Chemical pathways and speciated organic mass production, J. Geophys. Res., 109, D15205, doi:10.1029/2003JD004387, 2004a.

Ervens, B., Feingold, G., Clegg, S. L., and Kreidenweis, S. M.: A modeling study of aqueous production of dicarboxylic acids: 2. Implications for cloud microphysics, J. Geophys. Res., 109, D15206, doi:10.1029/2004JD004575, 2004b.

Gelencsér, A., Hoffer, A., Kiss, G., Tombácz, E., Kurdi, R., and Bencze, L.: In-situ formation of light-absorbing organic matter in cloud water, J. Atmos. Chem., 45, 25-33, 2003.

Glasius, M., Lahaniati, M., Calogirou, A., di Bella, D., Jensen, N. R., Hjorth, J., Kotzias, D., and Larsen, B. R.: Carboxylic acids in secondary aerosols from oxidation of cyclic monoterpenes by ozone, Environ. Sci. Technol., 34, 1001-1010, 2000.

Graedel, T. E. and Goldberg, K. I.: Kinetic-studies of raindrop chemistry 1 . Inorganic and organic processes, J. Geophys. Res., 88, 865-882, 1983.

Graedel, T. E., Mandich, M. L., and Weschler, C. J.: Kineticmodel studies of atmospheric droplet chemistry, 2. Homogeneous transition-metal chemistry in raindrops, J. Geophys. Res., 91, 5205-5221, 1986.

Gray, H. A.: Characteristics of atmospheric organic and elemental carbon particle concentration in Los Angeles, Environ. Sci. Technol. 20, 580-589, 1986.

Griffin, R. J., Cocker, D. R., Seinfeld, J. H., and Dabdub, D.: Estimate of global atmospheric organic aerosol from oxidation of biogenic hydrocarbons, Geophys. Res. Lett., 26, 2721-2724, 1999.

Grosjean, D., Grosjean, E., and Williams, E. L.: Atmospheric chemistry of unsaturated alcohols, Environ. Sci. Technol., 27, 2478-2485, 1993.

Hallquist, M., Wängberg, I., and Ljungström, E.: Atmospheric fate of carbonyl oxidation products originating from $\alpha$-pinene and $\Delta^{3}$-carene: Determination of rate of reaction with $\mathrm{OH}$ and $\mathrm{NO}_{3}$ radicals, UV absorption cross sections, and vapor pressures, Environ. Sci. Technol., 31, 3166-3172, 1997.

Herrmann, H., Ervens, B., Jacobi, H. W., Wolke, R., Nowacki, P., and Zellner, R.: CAPRAM2.3: A chemical aqueous phase radical mechanism for tropospheric chemistry, J. Atmos. Chem., 36, 231-284, 2000.

Hoffer, A., Kiss, G., Blazsó, M., and Gelencsér, A.: Chemical characterization of humic-like substances (HULIS) formed from a lignin-type precursor in model cloud water, Geophys. Res. Lett., 31, doi:10.1029/2003GL018962, 2004.

Hoffmann, T., Odum, J. R., Bowman, F., Collins, D., Klockow, D., Flagan, R. C., and Seinfeld, J. H.: Formation of organic aerosols from the oxidation of biogenic hydrocarbons, J. Atmos. Chem., 26, 189-222, 1997. 
Iinuma, Y., Böge, O., Gnauk, T., and Herrmann, H.: Aerosolchamber study of the $\alpha$-pinene $/ \mathrm{O}_{3}$ reaction: influence of particle acidity on aerosol yields and products, Atmos. Environ., 38, 761-773, 2004

Iraci, L. T., Baker, B. M., Tyndall, G. S., and Orlando, J. J.: Measurements of the Henry's law coefficients of 2-methyl-3-buten-2ol, methacrolein, and methylvinyl ketone, J. Atmos. Chem., 33, 321-330, 1999.

Jang, M. S., Czoschke, N. M., Lee, S., and Kamens, R. M.: Heterogeneous atmospheric aerosol production by acid-catalyzed particle-phase reactions, Science, 298, 814-817, 2002.

Kalberer, M., Paulsen, R. D., Sax, M., Steinbacher, M., Dommen, J., Prevot, A. S. H., Fisseha, R., Weingartner, E., Frankevich, V., Zenobi, R., and Baltensperger, U.: Identification of polymers as major components of atmospheric organic aerosols, Science, 303, 1659-1662, 2004.

Kawamura, K. and Sakaguchi, F.: Molecular distributions of water soluble dicarboxylic acids in marine aerosols over the Pacific Ocean including tropics, J. Geophys. Res., 104, 3501-3509, 1999.

Klippel, W. and Warneck, P.: Formaldehyde in rain water and on atmospheric aerosol, Geophys. Res. Lett., 5, 177-179, 1978.

Klotz, P. J., Kwok, E. S. C., Zhou, X., Lee, J. H., and Lee, Y.N.: A measurement technique for hydroxyacetone., in: Combined U.S./German Ozone/Fine Particle Science and Environmental Chamber Workshop, Mission Inn, Riverside, CA, Oct. 4-6, 1999.

König, G., Brunda, M., Puxbaum, H., Hewitt, C. N., Duckham, S. C., and Rudolph, J.: Relative contribution of oxygenated hydrocarbons to the total biogenic VOC emissions of selected midEuropean agricultural and natural plant species, Atmos. Environ., 29, 861-874, 1995.

Lelieveld, J. and Crutzen, P. J.: The role of clouds in tropospheric photochemistry, J. Atmos. Chem., 12, 229-267, 1991.

Lim, H. J. and Turpin, B. J.: Origins of primary and secondary organic aerosol in Atlanta: Results of time-resolved measurements during the Atlanta supersite experiment, Environ. Sci. Technol., 36, 4489-4496, 2002.

Limbeck, A., Kraxner, Y., and Puxbaum, H.: Gas to particle distribution of low molecular weight dicarboxylic acids at two different sites in Central Europe (Austria), J. Aerosol Sci., 36, 9911005, 2002.

Limbeck, A., Kulmala, M., and Puxbaum, H.: Secondary organic aerosol formation in the atmosphere via heterogeneous reaction of gaseous isoprene on acidic particles, Geophys. Res. Lett., 30, doi:10.1029/2003GL017738, 2003.

Meylan, W. M. and Howard, P. H.: Bond contribution method for estimating Henry's law constants, Environ. Toxicol. Chem., 10, 1283-1293, (http://www.syrres.com/esc/henry.htm), 1991.

Novakov, T., Hegg, D. A., and Hobbs, P. V.: Airborne measurements of carbonaceous aerosols on the East Coast of the United States, J. Geophys. Res., 102, 30 023-30 030, 1997.

Odum, J. R., Hoffmann, T., Bowman, F., Collins, D., Flagan, R. C., and Seinfeld, J. H.: Gas/particle partitioning and secondary organic aerosol yields, Environ. Sci. Technol., 30, 2580-2585, 1996.

Pandis, S. N., Paulson, S. E., Seinfeld, J. H., and Flagan, R. C.: Aerosol formation in the photooxidation of isoprene and $\beta$ pinene, Atmos. Environ., 25A, 997-1008, 1991.
Pankow, J. F.: An absorption-model of the gas aerosol partitioning involved in the formation of secondary organic aerosol, Atmos. Environ., 28, 189-193, 1994.

Penner, J. E., Andreae, M. O., Annegarn, H., Barrie, L., Feichter, J., Hegg, D., Jayaraman, A., Leaitch, R., Murphy, D., Nganga, J., and Pitari, G.: Aerosols, their Direct and Indirect Effects, in: Climate Change 2001: The Scientific Basis, contribution of Working Group I to the Third Assessment Report of the Intergovernmental Panel on Climate Change, edited by: Houghton, J. T., Ding, Y., Griggs, D. J., Noguer M., v. d. Linden, P. J., Dai, X., Maskell, K., and Johnson, C. A., Cambridge University Press, Cambridge, United Kingdom and New York, NY, USA, 881, 2001.

Pun, B. K., Seigneur, C., Grosjean, D., and Saxena, P.: Gasphase formation of water-soluble organic compounds in the atmosphere: A retrosynthetic analysis, J. Atmos. Chem., 35, 199223, 2000.

Ravishankara, A. R.: Heterogeneous and multiphase chemistry in the troposphere, Science, 276, 1058-1065, 1997.

Saxena, P. and Hildemann, L. M.: Water-soluble organics in atmospheric particles: A critical review of the literature and application of thermodynamics to identify candidate compounds, J. Atmos. Chem., 24, 57-109, 1996.

Schauer, J. J., Rogge, W. F., Hildemann, L. M., Mazurek, M. A., and Cass, G. R.: Source apportionment of airborne particulate matter using organic compounds as tracers, Atmos. Environ., 30, 3837-3855, 1996.

Seinfeld, J. H. and Pandis, S. N.: Atmospheric Chemistry and Physics, Wiley \& Sons, New York, 1998.

Sempéré, R. and Kawamura, K.: Low molecular weight dicarboxylic acids and related polar compounds in the remote marine rain samples collected from western Pacific, Atmos. Environ. 30, 1609-1619, 1996.

Stefan, M. I. and Bolton, J. R.: Reinvestigation of the acetone degradation mechanism in dilute aqueous solution by the UV/H2O2 process, Environ. Sci. Technol., 33, 870-873, 1999.

Strader, R., Lurmann, F., and Pandis, S. N.: Evaluation of secondary organic aerosol formation in winter, Atmos. Environ., 33, 48494863, 1999.

Turpin, B. J. and Huntzicker, J. J.: Secondary formation of organic aerosol in the Los Angeles basin: A descriptive analysis of organic and elemental carbon concentrations, Atmos. Environ., 25A, 207-215, 1991.

Warneck, P.: Chemistry of the Natural Atmosphere, Academic Press, 1988.

Warneck, P.: In-cloud chemistry opens pathway to the formation of oxalic acid in the marine atmosphere, Atmos. Environ., 37, 2423-2427, 2003.

Winiwarter, W., Fierlinger, H., Puxbaum, H., Facchini, M. C., Arends, B. G., Fuzzi, S., Schell, D., Kaminski, U., Pahl, S., Schneider, T., Berner, A., Solly, I., and Kruisz, C.: Henry's Law and the behavior of weak acids and bases in fog and clouds, J. Atmos. Chem., 19, 173-188, 1994.

Yu, J., Jefferies, H. E., and Le Lacheur, R. M.: Identifying airborne carbonyl compounds in isoprene atmospheric photooxidation products by their PFBHA oximes using gas chromatography/ion trap mass spectrometry, Environ. Sci. Technol., 29, 1923-1932, 1995. 